\title{
The metric dimensions of bridge graphs for some classes of graphs
}

\author{
Amrullah $^{1}$, Syahrul A. ${ }^{2}$, Turmuzi $\mathrm{M}^{3}$, Baidowi ${ }^{4}$, Nani $\mathrm{K}^{5}$ \\ \{amrullah@unram.ac.id ${ }^{1}$, syahrulazmi.fkip@unram.ac.id ${ }^{2}$, mturmuzi@unram.ac.id ${ }^{3}$, \\ baidowiunram@gmail.com ${ }^{4}$ nanikurniati.fkip@unram.ac.id $\left.{ }^{5}\right\}$ \\ Mathematics Education Departement, Universitas Mataram \\ Jln Majapahit no 62 Mataram, Indonesia ${ }^{1,2,3,4,5}$
}

\begin{abstract}
There are many open problems in the metric dimension of a graph, espessially the bridge graph and the disconnected graph, that have not been resolved until now. This paper presents the metrics dimension of the bridge graph in several classes of graphs namely cycle, complete, and star graphs. We know that the metric dimensions of the complete, cycle or star graph have been obtained. The bridge graph $B\left(G_{1}, G_{2}, e\right)$ is a graph which is obtained from the operation of adding edge $e$ to graphs $G_{1}$ and $G_{2}$. To obtain the metric dimension of the bridge graph from the graphs $G_{1}$ and $G_{2}$ on edge $e$, $p d\left(B\left(G_{1}, G_{2}, e\right)\right)$, we used the graph structure of $G_{1}, G_{2}$ and the properties of the bridge graph based on the endpoint on the edge e. The results obtained the metric dimension of the bridge graph $B\left(G_{1}, G_{2}, e\right)$ for the cycle, complete, or star graphs.
\end{abstract}

Keywords: Metric Dimension, Bridge Graph, Cycle Graph, Complete Graph, Star Graph

\section{Introduction}

The metric dimension is a concept that uses a revolving set. The resolving set is a set of vertices as a marker component that distinguishes all vertices on the graph. The concepts have used in several fields namely chemical structures [1], robot navigation [2], and optimization of combinations [3]. However, the applications cannot be used optimally because all the metric dimensions of the graph cannot be obtained yet. Therefore, several researchers conducted a study of metric dimensions in various ways, including the use of graph operations. Some graph operations that have been published are sum-product, cross-product operations, and corona product. The metric dimension of the cross product of path order $m$ with path order $2, P_{m} \times P_{2}$ [1], the cartesian product [4], and the corona product [5]. In addition to the metric dimension, some researchers use another variant to solve the problem of the dimension of the graph, namely partition dimensions. The partition dimension appears in many published articles, namely the partition dimension of subdivision homogeneous caterpillar [6], homogeneous firecrackers [7], subdivision of a Complete graph [8] and a complete multipartite graph [9].

To find the metric dimension of the graphs, there is also another interesting operation of the graph to study in the metric dimension, namely the bridge of two graphs. Therefore this paper shows the metric dimensions on some bridge graphs. The bridge graph is the result of the operation of two graphs connected by two vertices of the two graphs in the form of edges. In this paper, it is devoted to discussing the metric dimensions of bridge graphs formed from cycle graphs $C_{n}$, star graphs $K_{1, n}$ and the complete graph $K_{n}$. 


\section{Preliminaries}

Let $G=(V, E)$ be a connected graph.bridge graph and $v \in V(G)$. An ordered set of vertices $W=\left\{w_{1}, w_{2}, \cdots, w_{k}\right\} \subset V(G)$. The representation of $v$ respect to $W, r(v \mid W)$, is a vector $\left(d\left(v, w_{1}\right), d\left(v, w_{2}\right), \cdots, d\left(v, w_{k}\right)\right)$. The set $W$ is called the resolving set of $G$ if any two distinct vertices $x, y$, then $r(W) \neq r(y \mid W)$. The representation $r(x \mid W)$ and $r(y \mid W)$ are called the distinct if there is a component of the vector which is distinct, in other words, there is a $i$-component which is distinct, $d\left(x, w_{i}\right) \neq d\left(y, w_{i}\right)$ for some $i \in\{1,2, \cdots, k\}$. The basis of the bridge graph $G$ is a resolving set with the minimum cardinality. The metric dimension $G$, $\operatorname{dim}(G)$, is the cardinality of the basis of $G$. Let $x, y$ be two distinct vertices of $G$. If $d\left(x, w_{1}\right) \neq$ $d\left(y, w_{1}\right)$ then we say that the vertices $x$ and $y$ are distinguished by $w_{1}$.

\subsection{The Bridge Graph}

Let $G_{1}$ and $G_{2}$ be two connected graphs, $a \in V\left(G_{1}\right), b \in V\left(G_{2}\right)$. The bridge graph $B\left(G_{1}, G_{2}, a b\right)$ is a graph which is obtained from $G_{1}$ and $G_{2}$ with linking $a \in V\left(G_{1}\right)$ to $b \in$ $V\left(G_{2}\right)[10]$ For example, look at Figure 1.

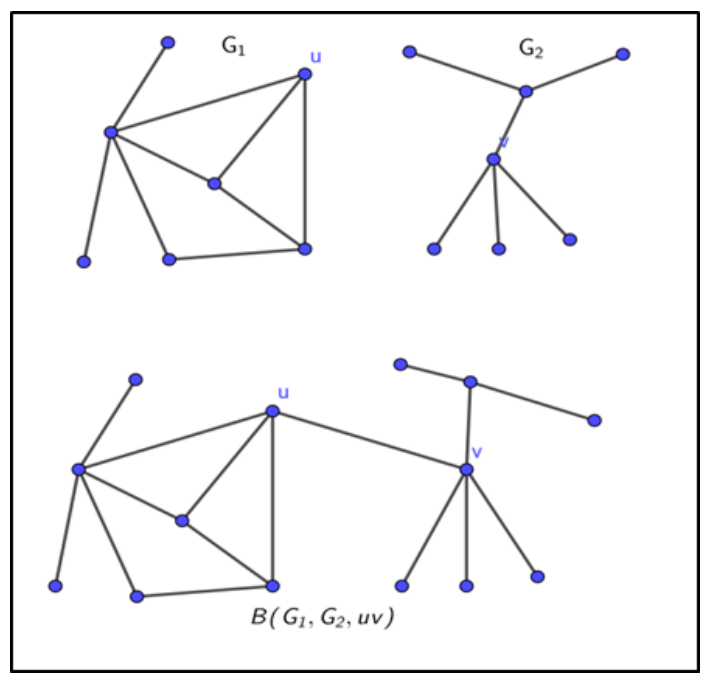

Fig. 1. The graphs $G_{1}, G_{2}$ and bridge graph $B\left(G_{1}, G_{2}, u v\right)$

\subsection{Basic concepts}

In section, we give some results of the metric dimension of the graph which is used in this research.

Theorem 1. [4]

Let $G$ and $P_{n}$ be a connected graph and a path graph of order $n$. The metric dimension $\operatorname{dim}(G)=$ 1 if and only if $G=P_{n}$. 
Theorem 2. [4]

Let $G$ and $K_{n}$ be a connected graph and a complete graph of order $n$. The metric dimension $\operatorname{dim}(G)=n-1$ if and only if $G=K_{n}$.

Referring to the Theorems 1 and 2, it can be obtained that other graphs of order $\mathrm{n}$ only have the metric dimensions from 2 to $n-2$.

\section{Lemma 1.}

If $G$ is a connected graph, then $p d(G) \leq \operatorname{dim}(G)+1$.

Lemma 1 gives the properties interconnection between the metric dimension and the partition dimension of the graphs.

\section{The Main Results}

This section discusses the metric dimensions of bridge graphs from three class graphs namely a cycle graph, a star graph, and a complete graph. The first result, we show that the metric dimension of bridge graf from two-cycle graphs is two, as in the following Theorem 3 . The cycle of order $n \geq 3, C_{n}$, is a regular graph of degree 2 and has $n$ edges.

\section{Theorem 3.}

If $C_{n}$ and $C_{m}$ are two-cycle graphs with $n, m \geq 3, \quad v_{1} \in V\left(C_{n}\right) ; u_{1} \in V\left(C_{m}\right)$, then $\operatorname{dim}\left(B\left(C_{n}, C_{m}, v_{1} u_{1}\right)\right)=2$.

Proof

Let $G=B\left(C_{n}, C_{m}, v_{1} u_{1}\right)$ and let $V\left(C_{n}\right)=\left\{v_{1}, v_{2}, v_{3}, \ldots, v_{n}\right\}$ be a vertices set of $C_{n}$, and $V\left(C_{m}\right)=\left\{u_{1}, u_{2}, u_{3}, \ldots, u_{m}\right\}$ be a vertices set of $C_{m}$. Since $B\left(C_{n}, C_{m}, v_{1} u_{1}\right)$ is not a path, then by Teorema 1 , we obtain

$$
\operatorname{dim}\left(B\left(C_{n}, C_{m}, v_{1} u_{1}\right)\right) \geq 2
$$

Suppose $W=\left\{v_{n}, u_{m}\right\} \subset V(G)$, We will prove that $W$ is a basis of $G$.

Let $x, y$ be two distinct vertices of $B\left(C_{n}, C_{m}, v_{1} u_{1}\right)$. To prove that $\operatorname{dim}\left(B\left(C_{n}, C_{m}, v_{1} u_{1}\right)\right) \leq$ 2 , we consider the vertices $x, y$ in two cases:

The first case. Suppose both $x, y \in C_{n}$.

Now we consider $d\left(x, v_{1}\right)$ and $d\left(y, v_{1}\right)$. If $d\left(x, v_{1}\right)=d\left(y, v_{1}\right)$, then clearly, $d\left(x, v_{n}\right) \neq$ $d\left(y, v_{n}\right)$. So we obtain $r(x \mid W) \neq r(y \mid W)$. Next, If $d\left(x, v_{1}\right) \neq d\left(y, v_{1}\right)$, then we have $d\left(x, u_{1}\right) \neq d\left(y, u_{1}\right)$. As a consequence, we have $d\left(x, u_{n}\right) \neq d\left(y, u_{n}\right)$. So we obtain $r(x \mid W) \neq r(y \mid W)$. Similarly, apply the same argument for $x, y \in C_{m}$. We obtain $r(x \mid W) \neq$ $r(y \mid W)$.

The second case. Suppose $x \in C_{n}$ and $y \in C_{m}$.

If $d\left(x, v_{n}\right)=d\left(y, v_{n}\right)$, then consider $d\left(x, u_{m}\right)$ and $d\left(y, u_{m}\right)$. Since $v_{n}, v_{1}, x \in V\left(C_{n}\right)$ and $v_{n}$ is adjacent to $v_{1}$, then $d\left(x, u_{m}\right)$ is at least $d\left(x, v_{n}\right)+1$. Whereas if $u_{m}, u_{1}, y \in V\left(C_{n}\right)$ and $u_{m}$ is adjacent to $u_{1}$, then $d\left(y, u_{m}\right)$ is at most $d\left(x, v_{n}\right)-1$. As a consequence, $d\left(y, u_{m}\right)<$ $d\left(x, u_{m}\right)$. Therefore, we have $r(x \mid W) \neq r(y \mid W)$. 
By these two cases, we have

$$
\operatorname{dim}\left(B\left(C_{n}, C_{m}, v_{1} u_{1}\right)\right) \leq 2
$$

As a consequence of these both two inequations (1) and (2), we obtain that the dimension of $B\left(C_{n}, C_{m}, v_{1} u_{1}\right)$ is 2 .

If the bridge graph is obtained from the star graph and the cycle graph, then the metric dimension of the bridge graph depends on the bridge edge. Next, the metric dimension is discussed in the following Theorem 4 . The star graph, $K_{1, n}$, is a tree with a vertex of degree $n$ and $n$ verices of degree 1 . The vertex of degree 1 is called the center of $K_{1, n}$ and the others are the leaves.

\section{Theorem 4.}

Let $K_{1, n}$ be a star and $C_{m}$ be a cycle graph.

If $a \in V\left(K_{1, n}\right)$ and $b \in V\left(C_{m}\right)$, then

$\operatorname{dim} \operatorname{dim}\left(B\left(K_{1, n}, C_{m}, a b\right)\right)=\left\{n n-1\right.$ if a is center of $K_{\{1, n\}}$ others .

\section{Proof}

Let $V\left(K_{1, n}\right)=\left\{u, u_{1}, u_{2}, u_{3}, \cdots, u_{n}\right\}, V\left(C_{m}\right)=\left\{v_{1}, v_{2}, v_{3}, \cdots, u_{m}\right\}$ and $G=B\left(K_{1, n}, C_{m}, a b\right)$ We consider the proof in two cases

Case 1. If $a=u$ and $b=v_{1}$, then we suppose $W=\left\{u_{1}, u_{2}, u_{3}, \cdots, u_{n-1}, v_{n}\right\}$.

We will show that $W$ is the basis of $G$.

Let $x, y$ be two distinct vertices of $G$. We consider two subcases

Subcase 1.1 the vertices $x, y \in V\left(C_{m}\right)$ or $x, y \in V\left(K_{1, n}\right)$. If $x, y \in V\left(K_{1, n}\right)$ and $x, y \notin W$ then $\{x, y\}=\left\{u, u_{n}\right\}$. So, the vertices $x$ and $y$ are distinguished by $v_{m}$. Next, we consider the vertices $x, y \in V\left(C_{m}\right)$. If $d\left(x, v_{m}\right) \neq d\left(y, v_{m}\right)$ then clearly $r(W) \neq r(y \mid W)$. Now, if If $d\left(x, v_{m}\right)=d\left(y, v_{m}\right)$ then we obtain $d\left(x, v_{1}\right) \neq d\left(y, v_{1}\right)$ because the vertex $v_{1}$ is adjacent to $v_{n}$ in $C_{m}$. As a consequence, we have $d\left(x, u_{1}\right) \neq d\left(y, u_{1}\right)$. So, we can say that $r(W) \neq$ $r(y \mid W)$.

Subcase 1.2 the vertex $x \in V\left(C_{m}\right)$ and $y \in V\left(K_{1, n}\right)$. If $x, y \in V\left(K_{1, n}\right)$ and $x, y \notin W$ If $d\left(x, v_{m}\right) \neq d\left(y, v_{m}\right)$, then the vertices $x, y$ are distinguished by $v_{m}$. So, we have $r(x \mid W) \neq$ $r(y \mid W)$. If $d\left(x, v_{m}\right)=d\left(y, v_{m}\right)$, then consider $y \in\left\{u, u_{n}\right\}$. If $y=u$ then $d\left(y, v_{-} m\right)=2$, Therefore, since $d\left(y, v_{m}\right)=2$ and $d\left(y, v_{m}\right)=d\left(x, v_{m}\right)$, then $x=v_{2}$ or $x=v_{m-2}$. Since $d\left(y, u_{1}\right)=1$ and $d\left(x, u_{1}\right) \geq 3$, then we obtain $d\left(y, u_{1}\right) \neq d\left(x, u_{1}\right)$. If $y=u_{n}$ then $d\left(y, v_{-} m\right)=2$, Therefore, $x=v_{2}$ or $x=v_{m-2}$. Since $d\left(y, u_{1}\right)=1$ and $d\left(x, u_{1}\right) \geq 3$, then we obtain $d\left(y, u_{1}\right) \neq d\left(x, u_{1}\right)$. Therefore, we have $r(x \mid W) \neq r(y \mid W)$. As these consequences of two subcases, we obtain that $W$ is a basis of $G$. So, we obtain $\operatorname{dim}(G) \leq n$.

Next, We show $\operatorname{dim}(G) \geq n$. Suppose $\operatorname{dim}(G)<n$.

Let $W$ be a basis of $G$. Since $\operatorname{dim}(G)<n$ then $|W|<n$. Let $W=\left\{a_{1}, a_{2}, \cdots, a_{t}\right\}$ with $t \leq$ $n-1$. If all vertices of $W$ are in the vertices of $K_{1, n}$ subgraph of $G$ then there are at least two vertices of $C_{m}$ subgraph of $G$ which have the same distance to all vertices of $W$ namely $v_{2}$ and $v_{m}$. So we have $r\left(v_{2} \mid W\right)=r\left(v_{m} \mid W\right)$, a contradiction. 
If there is at least one vertex of $W$ in $C_{m}$ subgraph of $G$. Suppose $a_{-} t$ in $C_{m}$ the and $a_{i}=u_{i}$ for $i=1,2, \cdots, t-1$. So, there are at least three vertices of $K_{1, n}$ subgraph of $\mathrm{G}$ which are not vertices of $W$. The three vertices of $K_{1, n}$ are $u, u_{n}$, and $u_{n-1}$. Consider the vertices $u_{1}$ and $u_{2}$, they have the same distance to all vertices of $W$. We have $r\left(v_{2} \mid W\right)=r\left(v_{m} \mid W\right)$, a contradiction. As the consequences, we obtain

$$
\operatorname{dim}(G) \geq n
$$

By inequations (3) and (4), we have $\operatorname{dim}(G)=n$.

Case 2. If $a=u_{n}$ and $b=v_{1}$, then we suppose $W=\left\{u_{1}, u_{2}, u_{3}, \cdots, u_{n-2}, v_{m}\right\}$.

We will show that $W$ is a basis of $G$

Let $x, y$ be two distinct vertices of $G$. We consider in two subcases

Subcase 1.1 the vertices $x, y \in V\left(C_{m}\right)$ or $x, y \in V\left(K_{1, n}\right)$. If $x, y \in V\left(K_{1, n}\right)$ and $x, y \notin W$ then $\{x, y\}=\left\{u, u_{n-1}\right\}$. So, the vertices $x$ and $y$ are distinguished by $v_{m}$. Next, we consider the vertices $x, y \in V\left(C_{m}\right)$. If $d\left(x, v_{m}\right) \neq d\left(y, v_{m}\right)$ then clearly $r(W) \neq r(y \mid W)$. Now, if If $d\left(x, v_{m}\right)=d\left(y, v_{m}\right)$ then we obtain $d\left(x, v_{1}\right) \neq d\left(y, v_{1}\right)$ because the vertex $v_{1}$ is adjacent ot $v_{n}$ in $C_{m}$. As a consequence, we have $d\left(x, u_{1}\right) \neq d\left(y, u_{1}\right)$. So, we can say that $r(W) \neq$ $r(y \mid W)$.

Subcase 1.2 the vertex $x \in V\left(C_{m}\right)$ and $y \in V\left(K_{1, n}\right)$. If $x, y \in V\left(K_{1, n}\right)$ and $x, y \notin W$. If $d\left(x, v_{m}\right) \neq d\left(y, v_{m}\right)$, then the vertices $x, y$ are distinguished by $v_{m}$. So, we have $r(x \mid W) \neq$ $r(y \mid W)$. If $d\left(x, v_{m}\right)=d\left(y, v_{m}\right)$, then consider $y \in\left\{u, u_{n-1}\right\}$. If $y=u$ then $d\left(y, v_{m}\right)=3$, Therefore, since $d\left(y, v_{m}\right)=3$ and $d\left(y, v_{m}\right)=d\left(x, v_{m}\right)$, then $x=v_{3}$ or $x=v_{m-3}$. Since $d\left(y, u_{1}\right)=1$ and $d\left(x, u_{1}\right) \geq 3$, then we obtain $d\left(y, u_{1}\right) \neq d\left(x, u_{1}\right)$, so, $r(W) \neq r(y \mid W)$. If $y=u_{n-1}$ then $d\left(y, v_{-} m\right)=4$, Therefore, $x=v_{4}$ or $x=v_{m-4}$. Since $d\left(y, u_{1}\right)=2$ and $d\left(x, u_{1}\right) \geq 4$, then we obtain $d\left(y, u_{1}\right) \neq d\left(x, u_{1}\right)$, so $r(W) \neq r(y \mid W)$.

Therefore, by two subcases, we have

$$
\operatorname{dim}(G) \leq n-1
$$

Next we will show dim dim $\geq n-1$.

Suppose $\operatorname{dim}(G) \leq n-2$.

Let $W$ be a basis of $G$. Since $\operatorname{dim}(G)<n$ then $|W|<n$. Let $W=\left\{a_{1}, a_{2}, \cdots, a_{t}\right\}$ with $t \leq$ $n-2$. If all vertices of $W$ are in the vertices of $K_{1, n}$ subgraph of $G$ then there are at least two vertices of $C_{m}$ subgraph of $G$ which have the same distance to all vertices of $W$ namely $v_{2}$ and $v_{m}$. So we have $r\left(v_{2} \mid W\right)=r\left(v_{m} \mid W\right)$, a contradiction.

If there is at least one vertex of $W$ in $C_{m}$ subgraph of $G$. Suppose $a_{-} t$ in $C_{m}$ the and $a_{i}=u_{i}$ for $i=1,2, \cdots, t-1$. So, there are at least three vertices of $K_{1, n}$ subgraph of $\mathrm{G}$ which are not vertices of $W$. The three vertices of $K_{1, n}$ are $u, u_{n}$, and $u_{n-1}$. Consider the vertices $u_{1}$ and $u_{2}$, they have the same distance to all vertices of $W$. We have $r\left(v_{2} \mid W\right)=r\left(v_{m} \mid W\right)$, a contradiction. As the consequences, we obtain

$$
\operatorname{dim}(G) \geq n-1
$$

By inequations (5) and (6), we have $\operatorname{dim}(G)=n-1$. 
In the next Theorem 5, we show the metric dimension of bridge graf from a complete graph and a cycle graph. The complete graph, $K_{n}$, is a graph formed by joining each pair of $n$ vertices [10].

\section{Theorem 5.}

Let $K_{n}$ be a complete graph and $C_{m}$ be a cycle. If $a \in V\left(K_{n}\right)$ and $b \in V\left(C_{m}\right)$, then $\operatorname{dim} \operatorname{dim}\left(B\left(K_{n}, C_{m}, a b\right)\right)=n-1$

Proof

Let $G=B\left(K_{n}, C_{m}, a b\right)$ and $V\left(K_{n}\right)=\left\{u_{1}, u_{2}, u_{3}, \cdots, u_{n}\right\}, V\left(C_{m}\right)=\left\{v_{1}, v_{2}, v_{3}, \cdots, u_{m}\right\}$

First, we will show $\operatorname{dim} \operatorname{dim}\left(B\left(K_{n}, C_{m}, a b\right)\right) \geq n-1$.

Suppose $\operatorname{dim} \operatorname{dim}\left(B\left(K_{n}, C_{m}, a b\right)\right) \leq n-2$. So there is a basis $\mathrm{W}$ of $\mathrm{G}$ with $|\mathrm{W}|=n-2$.

If all vertices of $W$ are contained in $V\left(K_{n}\right)$, then there are two vertices of $K_{n}$ which are not in $W$. We say that the vertices $u_{1}$ and $u_{2}$ are not in $W$. As a consequence, we have $d\left(u_{1}, z\right)=1$ and $d\left(u_{1}, z\right)=1$ for any $z \in W$. So we obtain $r\left(u_{1} \mid W\right)=r\left(u_{2} \mid W\right)$, a contradiction. If there is at least one vertex of $W$ which is contained in $V\left(K_{n}\right)$, then there are at least three vertices of $K_{n}$ which are not in $W$. So the vertices have the same representation, a contradiction. As a consequence we have

$$
\operatorname{dim} \operatorname{dim}\left(B\left(K_{n}, C_{m}, a b\right)\right) \geq n-1
$$

Next, we will show that $\operatorname{dim} \operatorname{dim}\left(B\left(K_{n}, C_{m}, a b\right)\right) \leq n-1$.

Let $V\left(K_{n}\right)=\left\{u_{1}, u_{2}, u_{3}, \cdots, u_{n}\right\}, \quad V\left(C_{m}\right)=\left\{v_{1}, v_{2}, v_{3}, \cdots, u_{m}\right\}, \quad a=v_{1} \quad$ and $b=u_{1}$. Suppose $W=\left\{v_{m}, u_{3}, u_{4}, \cdots, u_{n}\right\}$. We will show that $W$ is the basis of $G$.

Let $x, y$ be two distinct vertices of $G$ which are not in W. If the vertices $x, y \in V\left(C_{m}\right)$ then we consider the distance between the vertices $x, y$ to $v_{m}$. If $d\left(x, v_{m}\right) \neq d\left(y, v_{m}\right)$ then they are distinguished by $v_{m}$. If $d\left(x, v_{m}\right)=d\left(y, v_{m}\right)$ then $d\left(x, v_{1}\right) \neq d\left(y, v_{1}\right)$. Therefore, we obtain $d\left(x, v_{3}\right) \neq d\left(y, v_{3}\right)$. So the vertices $x, y$ are distinguished by $v_{3}$. Then, we have $r(W) \neq$ $r(y \mid W)$. If the vertices $x, y \in V\left(K_{n}\right)$ then $x=u_{1}$ and $y=u_{2}$. So, clearly, they are distinguished by $v_{m}$.

Next, we consider $x \in V\left(C_{m}\right)$ and $y \in V\left(K_{n}\right)$. We know $d\left(y, u_{3}\right)=1$ and $d\left(x, u_{3}\right) \geq 2$. The consequence, the vertices $\mathrm{x}, \mathrm{y}$ are distinguished by $u_{3}$. So we have $r(W) \neq r(y \mid W)$.

As the consequences, we obtain

$$
\operatorname{dim}(G) \leq n-1
$$

By inequations (7) and (8), we obtain $\operatorname{dim}(G)=n-1$

\section{Theorem 6.}

If $K_{1, n}$ is a star graph and $K_{m}$ is a complete graph with $n, m \geq 3, v \in V\left(K_{1, n}\right) ; u \in V\left(K_{m}\right)$, then $\operatorname{dim}\left(B\left(K_{1, n}, K_{m}, u v\right)\right)=\left\{(n+m)-4\right.$ if $v$ is a leaf of $K_{1, n}(n+m)-3$ others

Proof

Let $V\left(K_{m}\right)=\left\{u_{1}, u_{2}, \cdots, u_{m}\right\}$ and $V\left(K_{1, n}\right)=\left\{v_{1}, v_{2}, \cdots, v_{n,}, c\right\}$ where $c$ is a non-leaf of $K_{1, n}$ Let $G=B\left(K_{1, n}, K_{m}, u v\right)$. we consider the vertex $u$ in two cases.

Case 1. The vertex $v$ is a leaf of $K_{1, n}$ We will show that $\operatorname{dim}\left(B\left(K_{1, n}, K_{m}, u v\right)\right) \leq(n+m)-4$. 
Since $v$ is a leaf, so we suppose $u=u_{1}, v=v_{1}$ and $W=\left\{u_{3}, u_{4}, \cdots, u_{m}\right\} \cup\left\{v_{3}, v_{4}, \cdots, v_{n}\right\}$ where $|W|=n+m-4$. We will show that $W$ is the basis of $G$. Let $x, y$ be two distinct vertices of $G$. Since there are only five vertices of $G$ which are not in $W$ namely $c, v_{1}, v_{2}, u_{1}, u_{2}$, then clearly, they have a different representation of $W, r(W) \neq r(y \mid W)$. As a consequence, we have

$$
\operatorname{dim}\left(B\left(K_{1, n}, K_{m}, u v\right)\right) \leq(n+m)-4
$$

Next, we will show that $\operatorname{dim}\left(B\left(K_{1, n}, K_{m}, u v\right) \geq(n+m)-4\right.$. In another word, There is a $W \subset$ $V(G)$ as a basis of $\mathrm{G}$ such that $|W| \geq m+n-4$.

Suppose $\operatorname{dim}\left(B\left(K_{1, n}, K_{m}, u v\right)\right)<(n+m)-4$. So, we have a basis W such that $|W|=m+$ $n-5$. Since the order of $G$ is $n+m+1$, then there are at least six vertices of $G$ that are not in W. we say the vertices $H=\left\{h_{1}, h_{2}, h_{3}, h_{4}, h_{5}, h_{6}\right\} \subset V(G)$ and every $h_{i} \notin W$ for $i \in$ $\{1,2, \ldots, 6\}$.

We will show that there are at most two vertices $h_{i} \in V\left(K_{n}\right)$. Suppose there are three vertices $h_{1}, h_{2}, h_{3} \in H$ and $h_{i} \in V\left(K_{n}\right)$. Let $h_{1}=u$. So, we have $d\left(h_{2}, W\right)=d\left(h_{3}, W\right)$, a contradiction of $W$ as a basis of $G$.

The second, Since there are at most two vertices $h_{i} \in V\left(K_{n}\right)$, we say $h_{1}$ and $h_{2} \in V\left(K_{-} n\right)$, then there are four vertices $h_{3}, h_{4}, h_{5}, h_{6}$ of $\mathrm{H}$ which are in the $V\left(K_{1, n}\right)$. Let $h_{3}=c$ and $h_{4}=v$. Now, we consider vertices $h_{5}, h_{6}$ which are a leaf of $K_{1, n}$. As a consequence, we have $d\left(h_{5}, W\right)=d\left(h_{6}, W\right)$, a contradiction of $W$ as a basis of $G$.

These consequences, we obtain

$$
\operatorname{dim}\left(B\left(K_{1, n}, K_{m}, u v\right)\right) \geq(n+m)-4
$$

By inequations (9) and (10), we obtain $\operatorname{dim} \operatorname{dim}\left(B\left(K_{1, n}, K_{m}, u v\right)\right)=(n+m)-4$.

Case 2. The vertex $u$ is not a leaf of $K_{1, n}$. So we have $u=c$. We will show that $\operatorname{dim}\left(B\left(K_{1, n}, K_{m}, u v\right)\right) \leq(n+m)-3$. Since $v$ is not a leaf, so we have $v=v_{1}$. Let $u=u_{1}$ and $W=\left\{u_{3}, u_{4}, \cdots, u_{m}\right\} \cup\left\{v_{2}, v_{3}, v_{4}, \cdots, v_{n}\right\}$ where $|W|=n+m-3$. We will show that $W$ is a basis of $G$. Let $x, y$ be two distinct vertices of $G$. Since there are only four vertices of $G$ which are not in $W$ namely $c, v_{1}, u_{1}, u_{2}$, then clearly, they have a different representation of $W$, $r(W) \neq r(y \mid W)$.

As a consequence, we have

$$
\operatorname{dim}\left(B\left(K_{1, n}, K_{m}, u v\right)\right) \leq(n+m)-3
$$

Next, we will show that $\operatorname{dim}\left(B\left(K_{1, n}, K_{m}, u v\right) \geq(n+m)-3\right.$. In other words, There is a $W \subset$ $V(G)$ as a basis of $\mathrm{G}$ such that $|W| \geq m+n-3$.

Suppose $\operatorname{dim}\left(B\left(K_{1, n}, K_{m}, u v\right)\right)<(n+m)-3$. So, we have a basis W such that $|W|=m+$ $n-4$. Since the order of $G$ is $n+m+1$, then there are at least five vertices of $G$ that are not in $W$. we say the vertices $H=\left\{h_{1}, h_{2}, h_{3}, h_{4}, h_{5}\right\} \subset V(G)$ and every $h_{i} \notin W$ for $i \in\{1,2, \ldots, 5\}$. We will show that there are at most two vertices $h_{i} \in V\left(K_{n}\right)$. Suppose there are three vertices $h_{1}, h_{2}, h_{3} \in H$ and $h_{i} \in V\left(K_{n}\right)$. Let $h_{1}=u$. So, we have $d\left(h_{2}, W\right)=d\left(h_{3}, W\right)$, a contradiction of $W$ as a basis of $G$. 
The second, Since there are at most two vertices $h_{i} \in V\left(K_{n}\right)$, we say $h_{1}$ and $h_{2} \in V\left(K_{-} n\right)$, then there are four vertices $h_{3}, h_{4}, h_{5}$ of $H$ which are in the $V\left(K_{1, n}\right)$. Let $v=h_{3}=c$. Now, we consider vertices $h_{4}, h_{5}$ which are a leaf of $K_{1, n}$. As a consequence, we have $d\left(h_{4}, W\right)=$ $d\left(h_{6}, W\right)$, a contradiction of $W$ as a basis of $G$.

These consequences, we obtain

$$
\operatorname{dim}\left(B\left(K_{1, n}, K_{m}, u v\right)\right) \geq(n+m)-3
$$

By inequations (11) and (12), we obtain $\operatorname{dim} \operatorname{dim}\left(B\left(K_{1, n}, K_{m}, u v\right)\right)=(n+m)-3$.

Acknowledgments. We would like to thank for the support and funding of University of Mataram and the research grants Penelitian Dasar Unggulan Perguruan Tinggi, Ristek Dikti, Indonesia.

\section{References}

[1] Chartrand, G. and Lesniak, L.: Graf and Digraph Third Edition. California: Wadswoth, Inc. Combinatoria, Vol. 2. pp. 191-195 (1996)

[2] Khuller, S., Raghavachari, B. and Rosenfeld, A.: Landmarks in Graphs. Discrete Appl. Math, Vol. 70, pp. 217-229 (1996)

[3] Sebo, A. and Tannier, E.: On Metric Generators of Graphs. Journal Mathematics of Operations Research Vol. 29, No. 2 (2004)

[4] Chartrand, G, L. Eroha, M. A. Johnsonb and O. R. Oellermann.: Resolvability in graphs and the metric dimension of a graph, Discrete Applied Mathematics, Vol. 105, pp. 99-113 (2000)

[5] Yero I.G., Kuziak D. and Rodríguez-Velázqueza.: On the metric dimension of corona product graphs, Computers \& Mathematics with Applications, Vol. 61, No. 9, pp. 2793-2798 (2011)

[6] Amrullah, H. Assiyatun, E. T. Baskoro, S. Uttunggadewa and R. Simanjuntak.: The Partition Dimension for a Subdivision of Homogeneous Caterpillars, AKCE International Journal of Graphs and Combinatorics, Vol. 10, pp. 317-325 (2013)

[7] Amrullah, Darmaji and Edy Tri Baskoro.: The partition dimension for homogeneous firecrackers, Far East Journal of Applied Mathematics, Vol. 90, pp. 77 - 98 (2015)

[8] Amrullah, E. T. Baskoro, S. Rinovia and S. Uttunggadewa.: The Partition Dimension of a Subdivision of a Complete Graph, Procedia Computer Science, Vol. 74, pp. 53-59 (2015)

[9] Darmaji, S. Uttunggadewa, R. Simanjuntak and E. T. Baskoro.: The partition dimension of a complete multipartite graph, a special caterpillar and a windmill, J. Combin. Math. Combin.Comput., Vol. 71, pp. 209-215 (2009)

[10] Wallis, W. D.: A Beginer's Guide to Graph Theory. Birkhäuser Boston Inc., Boston, MA, second edition (2007) 